\title{
Farmers' willingness to pay for a village poultry vaccine service in Ethiopia: prospect for enhancing rural livelihoods
}

\author{
Z. G. Terfa ${ }^{1,2} \cdot$ S. Garikipati ${ }^{1}$ - T. Dessie ${ }^{2}$ - S. Lynch $^{3,2}$. \\ P. Wigley ${ }^{3} \cdot$ J. M. Bettridge ${ }^{3,2} \cdot$ R. M. Christley ${ }^{3}$
}

Received: 5 July 2014 / Accepted: 14 June 2015 /Published online: 30 June 2015

(C) The Author(s) 2015. This article is published with open access at Springerlink.com

\begin{abstract}
This research examines farmers' willingness to pay for village poultry vaccine programmes using data from 400 household heads from two districts in Ethiopia, Horro and Jarso. The study applied a contingent valuation method to elicit farmers' willingness to pay for village poultry vaccine services. Two hypothetical vaccine programmes were designed for Newcastle disease and Gumboro disease. Both parametric and non-parametric approaches were employed in data analysis. The results show that farmers recognise the benefits of the vaccine programme and that many would be willing to pay for it. Results from non-parametric estimates produced households' mean willingness to pay Ethiopian Birr (ETB) 80 up to ETB 87 per year based on vaccine programme type. This demonstrates the potential and prospect of reducing the impact of infectious poultry diseases and enhancing rural livelihoods through village poultry. Exponential probit analysis revealed that farmers' willingness to pay for village poultry vaccine service is influenced by age, education level, and region of respondents. Younger and more-educated farmers were more likely to pay for village poultry vaccine services and farmers from Horro, a relatively food secure and educated
\end{abstract}

Z. G. Terfa

zedgutu@gmail.com

1 Management School, University of Liverpool, Chatham Street, Liverpool L69 7ZH, UK

2 International Livestock Research Institute, P.O.Box 5689, Addis Ababa, Ethiopia

3 Institute of Infection and Global Health, Department of Epidemiology and Population Health, University of Liverpool, Leahurst Campus, Chester High Road, Neston, Cheshire CH64 7TE, UK area, were more likely to pay than those from the less food secure Jarso district.

Keywords Willingness to pay $\cdot$ Poultry vaccine $\cdot$ Newcastle disease $\cdot$ Gumboro disease

\section{Introduction}

In many developing countries, livestock in mixed croplivestock farming systems are of crucial importance to both household and national economies. Family poultry constitute an important component of the agricultural and household economy in the developing world (Gueye 2002). Rural poultry production is an important agricultural activity in almost all developing communities in Africa, providing animal protein in the form of meat and eggs, as well as being a reliable source of cash. In Ethiopia, village chickens provide major opportunities for increased protein supply and income for smallholders (Aklilu et al. 2007; Halima et al. 2007) because they require low capital investment, have a short generation interval and a high rate of reproduction. However, the village poultry production system in Ethiopia is characterised by small flock sizes, low input and output and is substantially impacted by disease.

Whether the livestock sector attains its full productive potential is heavily influenced by the availability and quality of animal health services. Poor health in animal herds and flocks, however, constrains livestock development in many countries (Umali et al. 1994). Infectious and parasitic diseases affecting livestock remain important constraints to profitable livestock operations in many developing regions (Delgado et al. 1999). This adversely affects animal welfare and often has major impacts upon human health and public perception of livestock production. The costs of existing endemic diseases are 
estimated to be 35 to $50 \%$ of the turnover of livestock in the developing world (Whitelaw and Sang 2005). In Ethiopia, poultry diseases are considered to be the most important factor responsible for reducing both the number and productivity of chickens. In the year 2010/11 alone, some 42.3 million poultry died of diseases and other causes according to an agricultural sample survey on livestock and livestock characteristics (CSA 2011). There has been neither a policy to control village poultry diseases nor adequate information available to policy makers, despite continued high prevalence and severe impact of infectious diseases among village chicken populations in the country.

Studies indicate that poultry diseases such as Newcastle disease, Infectious bursal disease (IBD), and coccidiosis are endemic in village poultry and are believed to cause huge economic losses to village poultry keepers in rural Ethiopia (Dessie and Ogle 2001; Gari et al. 2008). Findings from recent studies suggest that Newcastle disease and IBD are widespread in rural Ethiopia (Degefu et al. 2010; Jenbreie et al. 2012; Zeleke et al. 2005) and hence these diseases, both of which are known to cause high mortalities, are important bottlenecks to village poultry development. Well-tested vaccines exist that can be used as a preventive measure in less than optimal field conditions, and applied even without injection, and they enable individual farmers to protect their flocks (McLeod and Rushton 2007). Studies on application of vaccines in village poultry in developing countries also show the possibility of effectively controlling Newcastle disease (Msoffe et al. 2010; Wambura et al. 2000; Copland and Alders 2005).

The National Veterinary Institute of Ethiopia produces a variety of vaccines for poultry diseases. However, village poultry producers have no or limited access to these vaccines, despite their efficacy in reducing chicken mortality (Copland and Alders 2005). Notwithstanding the potential marketability of these vaccine services, they are yet to be marketed in the country. Contingent valuation method (CVM) is a widely used stated preference approach to value non-market goods (Mitchell and Carson 1989). It is widely applied in areas of environmental economics (Hanemann 1984; Loomis et al. 2000) and is also applied in other areas of research, such as development economics and health economics (Johannesson et al. 1991; Merrett 2002). Valuation methods are increasingly being applied to livestock research for valuation of traits in indigenous livestock breeds and disease resistance (Kassie et al. 2009; Ouma et al. 2007; Scarpa et al. 2003a); however, application of valuation techniques to evaluate willingness to pay for livestock vaccines and related services to inform disease control policy is quite limited. A study by Swallow and Woudyalew (1994) which estimates willingness to pay (WTP) for tsetse fly control in Ethiopia using CVM is among the few valuation studies employed in livestock disease control. A more recent work is that of Bennett and Balcombe (2012) who used both CVM and choice experiment to assess cattle farmers' WTP for a bovine tuberculosis cattle vaccine in England and Wales.

Provision of animal health service, at least at recovery cost, is indispensable for sustainability of intervention. Community participation, by devoting their financial and time resources, is crucial for the success and sustainability of such projects. In this study, therefore, we are interested in evaluating smallholders' interest and WTP for periodic vaccination of village poultry. Both parametric and non-parametric approaches were used to evaluate farmers' willingness to pay, using data collected through a contingent valuation survey. This study aims to contribute to the body of knowledge in the area of livestock disease control policy under a low-input-low-output production system by employing a stated preference valuation method to estimate WTP for vaccine services. Therefore, this study gives important insight into an effort to reduce impacts of infectious diseases in a village poultry production system across developing countries.

\section{Materials and methods}

\section{The contingent valuation method and designing process}

Contingent valuation method is a survey-based technique for eliciting preferences for non-marketed goods in a form which allows one to estimate how survey respondents trade-off private consumption for a non-marketed good in monetary terms (Carson 1998). A vaccination service might be deemed to be a private good and potentially marketable. In the context of the Ethiopian livestock health service system, however, vaccination of village poultry has never been tried and it is not part of veterinary services provided by the government. Umali et al. (1994) also noted that many animal health inputs are neither purely private nor purely public. The use of vaccines and veterinary pharmaceuticals involves externalities. Vaccination programmes are private goods whose consumption produces externalities. Vaccinations protect animals from disease and the farmer who owns the vaccinated animal(s) is the sole beneficiary of the procedure where no one else is able to benefit from the service during that time. The externality arises because the procedure may reduce the risk of exposure of other animals (and humans in the case of zoonoses) to the disease. In village poultry production where chickens from different households scavenge together, externality and spillover effects are obvious. Therefore, village poultry vaccination involves (positive) externality and the vaccine is a new product yet to be marketed. CVM is widely used in economic valuation of non-marketed goods as it uses choice and consumer preference as its underlying logic of valuation.

CVM is used in wider disciplines in developed countries and it has also been applied in developing countries mainly to elicit individuals' preferences for basic infrastructural projects 
such as water supply and sanitation (e.g., Merrett 2002; Whittington et al. 1990). Despite the wider use of CVM, there is concern regarding reliability and validity of the responses. According to Carson et al. (1996), however, the majority of WTP estimates for use values based on CVM pass the test of validity involving comparisons of values derived from actual behaviour methods. Brouwer et al. (2008) in their study on economic valuation of flood risk exposure and flood control in developing countries also carried out a test-retest six months after the original survey and showed that the stated WTP values were reliable.

Selection of elicitation format is one of the contentious aspects of CVM. While dichotomous-choice is likely the most favoured format, open-ended, multiple-bounded and payment card are also possible elicitation techniques. In addition to being less realistic and harder to answer, the open-ended format creates incentives which are different from those in the closed-ended format. With the open-ended format there are strategic reasons for stating less than one's full value which is not the case in closed-ended format (Hanemann 1994). Close-ended valuation questions are typically desirable to valuing hypothetical public good (Arrow and Solow 1993; Hanemann 1984; Mitchell and Carson 1989). Therefore, we used a close-ended elicitation framed as a dichotomous choice. In order to make the contingent valuation questionnaire more reliable, a 'don't know' response option was included in addition to 'Yes/No'. The close-ended elicitation question was followed by a debriefing question to check respondents' understanding and acceptance of the aspects of the scenarios presented to them. The wordings (in English) of the scenarios read to the respondents are given in the Appendix. These were read to the respondents in Afan Oromo, a language spoken in both study areas.

For contingent valuation to work, the non-marketed good must be well defined, the scenario must provide a plausible means of provision, and there must exist a plausible mechanism for making the trade-off between the consumption of private goods and the non-marketed good of interest (Carson 1998). Similarly, Hanemann (1994) addressed areas ${ }^{1}$ including sampling, instrument development, formulation of the valuation scenario, questionnaire structure, and data analysis to enhance the credibility of a survey and make it more likely to produce reliable results. In this study the design of contingent valuation process involved a number of steps to ensure that the hypothetical scenario we developed was understandable and meaningful from smallholder farmers' perspective, workable in the existing production system and able to produce reliable willingness to pay estimate.

Prior to formally designing the scenarios, an interdisciplinary project team conducted two focus group discussions in

\footnotetext{
${ }^{1}$ See Hanemann (1994) for good summary of all these aspects.
}

January 2011 in each of the two districts to explore the village poultry production system and existing animal health services and to see how farmers understood and responded to scenarios. The focus groups consisted of 15-20 farmers in each village. Findings of these group discussions were used to further develop the scenario and describe the programme. The interdisciplinary team (consisting of epidemiologists, microbiologists, poultry breeders and geneticists, and economists) worked together to develop improved contingent valuation scenarios in consultation with local Livestock Agency experts. The National Veterinary Institute was also consulted on the country's capacity to produce the vaccines that were included in the programme. The vaccine products we considered in the programme included Newcastle diseases vaccine (thermostable) and Gumboro vaccine. The vaccine programme was designed for these two diseases based on their prevalence in village poultry in the country. We relied on past studies (Zeleke et al. 2005; Degefu et al. 2010; Jenbreie et al. 2012) and field observation by animal health experts to identify these prevalent and important infectious diseases in the village poultry. Two scenarios were designed: one scenario was designed to deliver the vaccination service through village animal health extension workers, whereas the other scenario included training of farmers to vaccinate their birds themselves. Considering the village poultry production system, periodic outbreak of diseases and to attain optimum control of the diseases, both scenarios were designed to deliver vaccine services three times a year. Detailed descriptions of the two scenarios were finally developed for pre-test.

The final draft scenarios were pre-tested on individual farmers in February 2011. Further changes were made mainly on sequence of the scenarios and other parts of the questionnaire. The questionnaire was arranged in three sections and the two scenarios were presented to respondents in random order. The first section contained a statement of consent for the respondent and some warm-up questions to elicit demographic data of the respondent and information regarding the respondent's knowledge about poultry heath and health services. The second section contains the two contingent valuation scenarios and related questions. In this section, four different bid levels, the proposed price for the vaccine service scenario, were filled in each of the two scenarios. The bid levels used in scenario one were Ethiopia Birr ${ }^{2}$ (ETB) 65, 95, 125, and 155 and for the second scenario the bid levels were ETB 55, 85,110 , and 135 . These bid amounts were chosen based on results from the focus group discussion, pilot survey and in consultation with the National Veterinary Institute on vaccine cost data. The third section recorded respondents' general socioeconomic data.

\footnotetext{
${ }^{2}$ Birr is the currency of Ethiopia; 1 USD $\approx 17$ ETB during survey period
} 


\section{Statistical model}

A number of statistical procedures are available to model single bounded discrete response contingent valuation. Parametric and non-parametric models are the two possible statistical tools for analysis of discrete response CVM data. The use of a parametric distribution to approximate the distribution of WTP in a sample represents a fairly large assumption (Bateman et al. 2002). When the pattern of responses is well behaved (i.e., changes in line with demand theory), the estimates of willingness to pay (WTP) will not be sensitive to the choice of distributional assumptions for the unobserved random component of preference or functional form of the preference function (Haab and McConnell 2002). When the objective is to estimate the mean and median values of the WTP distribution, the analyst can turn to an alternative estimation framework, a nonparametric estimation (Bateman et al. 2002).

When samples are sufficiently large to minimise random error, the proportion of observed 'No' responses to each bid should increase as the offered price increases. However, this assumes that responses are in line with demand theory, and hence in practice this is not guaranteed and non-monotonic empirical distribution functions for some of the offered prices are often observed. Randomness in response often leads to non-monotonic distribution of a 'No' response. One of the available options in this case is to impose a monotonicity restriction on distributionfree estimators and apply the Turnbull distribution free estimator (Haab and McConnell 2002). As can be seen in the next section, the responses to the discrete response to contingent valuation in our data had a similar problem and we applied this method as a remedy. We present the derivation of Turnbull estimator following Haab and McConnell (1997).

Respondents are asked to pay $c_{j}$ amount of money where $j=0,1, \ldots M$ and $c_{0}=0 ; c_{j}>c_{k}$. Let $p_{j}$ be the probability that the respondent's willingness to pay (WTP) is in the interval $c_{j-1}$ to $c_{j}$. This can be expressed as $p_{j}=p\left(c_{j-1}<W T P \leq c_{j}\right)$ for $j=1, \ldots$ $M+1$. It is assumed that $c_{M+1}=\infty$. The cumulative distribution function is written as:

$F_{j}=p\left(W T P \leq c_{j}\right)$ for $j=1, \ldots M+1$, where $F_{m+1}=1$.

Then $p_{j}=F_{j}-F_{j-1}$ and $F_{0}=0$. Here $p_{j}$ can be considered as the response to price increase and they should be positive because a higher proportion of respondents should answer 'No' at a higher price.

The log-likelihood function in terms of the probability mass point $\left(p_{1}, p_{2}, \ldots p_{M}, p_{M+1}\right)$ is

$$
\begin{aligned}
& \mathrm{L}(p \mid Y, N, T) \\
& \quad=\sum_{j=1}^{M}\left[N_{j} \ln \left(\sum_{i=1}^{j} p_{k}\right)+Y_{j} \ln \left(1-\sum_{i=1}^{j} p_{k}\right)\right]
\end{aligned}
$$

Where $N_{j}=$ number of respondents who respond 'No' to $c_{j}$ and $Y_{j}=$ number of respondents who respond 'Yes' to $c_{j}$.
This equation constrains the sum of $p_{j}$ to one. However, $p_{j}$ must be non negative and fall within the unit interval to constitute a valid density function. The first order condition for the problem, (4), takes the form

$$
\begin{gathered}
\partial L / \partial p_{i}=\sum_{j=i}^{m}\left(N_{j} / \sum_{k=1}^{j} p_{k}-Y_{j} /\left(1-\sum_{k=1}^{j} p_{k}\right)\right) \leq 0, \\
p_{i} \geq 0, \quad p_{i} \ln \partial L / \partial p_{i}=0
\end{gathered}
$$

To find the solution to the likelihood maximization problem, the set of first-order conditions must be solved recursively. By construction, the maximum likelihood problem ensures that $p_{1}>0$ so long as $N_{1} \neq 0$. Therefore, the first order condition for $p_{1}$ holds with equality so long as at least one respondent responded 'No' to $c_{1}$. With this assumption, solve for $p_{1}$ by assuming for the moment that $p_{1} \neq 0$. The first two first order conditions now hold with equality and can be differenced. The Turnbull estimator treats each group of individuals offered the same bid as a series of independent Bernoulli trials. The probability that willingness to pay falls below the bid amount, when proportion of 'No' response to $c_{i}$ is greater than proportion of 'No' response to $c_{i-1}$, is the binomial probability given as;

$$
F_{j}=N_{j} /\left(N_{j}+Y_{j}\right)
$$

When the proportion of 'No' response to $c_{i-1}$ is greater than proportion of 'No' response to $c_{i}$, the unconstrained maximum likelihood estimate for $p_{j}$. will be negative. We need to impose a non-negativity constraint and the Kuhn-Tucker solution to the problem of a binding non negativity constraint for $p_{j}$ is to combine $j^{\text {th }}$ and $(j-1)^{\text {th }}$ cells. Then, defining $N_{j}^{*}=N_{j}+$ $N_{j-1}$. and $Y_{j}^{*}=Y_{j}+Y_{j-1}, P_{j}$ could be estimated as;

$P_{j}=N_{j}^{*} /\left(N_{j}^{*}+Y_{j}^{*}\right)-\sum_{k=1}^{j-2} p_{k}$

If $P_{j}$ is still negative, then this process is repeated until a position $P_{j}$ is nonnegative. This pooled adjacent violator algorithm (PAV) technique was used to obtain cumulative density function (CDF) and probability density function (PDF) to calculate distribution free lower bound willingness to pay.

The variance of the $P_{j}$ can be calculated manually as:

$$
\begin{aligned}
V\left(P_{j}\right)= & F_{j}\left(1-F_{j}\right) /\left(N_{j}+Y_{j}\right) \\
& +F_{j-1}\left(1-F_{j-1}\right) /\left(N_{j-1}+Y_{j-1}\right)
\end{aligned}
$$

The central tendency measure of welfare in the Turnbull estimator is a lower bound approximation to expected willingness to pay. The conservative nature of this nonparametric approach and the ease with the estimation and welfare calculation are attractive features (Haab and McConnell 1997). The 
lower bound willingness to pay and its variance can be calculated from the expression,

$$
\begin{aligned}
& E_{L B}(W T P)=\sum_{j=1}^{M} c_{j}^{*} p_{j+1} \\
& V\left(E_{L B}(W T P)\right)=\sum_{j=1}^{M} V\left(F_{j}\right)\left(c_{j}-c_{j-1}\right)^{2}
\end{aligned}
$$

The principal drawback to nonparametric approaches lies in the difficulty in making inferences based on parameters (Haab and McConnell 1998). In the parametric approach, on the other hand, evaluating mean WTP from different distributional assumption may give very different values. One important guideline in estimating average WTP is to use bid function rather than utility difference model (Bateman et al. 2002). According to Haab and McConnell (1998) also, one solution to problems with the random utility model is to specify choice in terms of the willingness to pay function. When the unrestricted parametric estimate provides either negative or too high expected WTP, a reasonable strategy ought to be a conservative approach. A conservative approach, when there are concerns about the distribution of response data, is to calculate the sample mean using the Turnbull lower bound and then estimate an exponential willingness to pay function and calculate its median (Haab and McConnell 2002). In this study, therefore, we used Probit exponential willingness to pay function to estimate median WTP and to estimate the effect of bid prices and respondents' socioeconomic characteristics on willingness to pay. The exponential willingness to pay with linear combination of attributes and additive stochastic preference term is

$W T P_{j}=\exp \left(\gamma z_{j}+\eta_{j}\right)$

Where $\eta_{j}$. is a stochastic error with mean zero and unknown variance, $\sigma^{2}$. The probability that individual $j$ responding 'Yes' for an offered bid $c_{j}$ is equivalent to the probability of the random willingness to pay function is greater than the offered bid:

$$
\begin{aligned}
P\left(\text { yes }_{j}\right)= & P\left(W_{T P}>c_{j}\right) \\
& =P\left(\exp \left(\gamma z_{j}+\eta_{j}\right)>c_{j}\right) \\
& =P\left(\eta_{j}>\ln \left(c_{j}\right)-\gamma \mathbf{z}_{j}\right)
\end{aligned}
$$

Normalizing by the unknown standard errors, $\sigma$, to standardize the stochastic error the probability is

$P\left(W T P_{j}>c_{j}\right)=P\left(\theta_{j}>\beta \ln \left(c_{j}\right)-\gamma^{*} \mathbf{z}_{j}\right)$

Where $\theta_{j}=\eta_{j} / \sigma, \beta=1 / \sigma$ and $\gamma^{*}=\gamma / \sigma$.

Assuming the error term, $\eta_{j}$, is normally distributed with mean zero and constant variance, $\sigma^{2}$, a probit model can be estimated. A median willingness to pay can be obtained from the estimated probit model using the expression

$M D_{\eta}\left(W T P \mid \mathbf{z}_{j}, \gamma\right)=\exp \left(\gamma \mathbf{z}_{j}\right)$

The exponential willingness to pay was estimated using a probit regression model. The bid levels were randomly presented to respondents and the socioeconomic variables were used as covariates in the estimated model. Most of the variables used in the model are presented in Table 1. In addition to these variables, region of the respondent was also included in explanatory variables, with value 1 if Horro and 0 if Jarso. We included this variable to account for differences in agro-ecology and socio-culture of the two study areas. Farmers' perception of effectiveness of the proposed vaccine programme was also among the covariates used in the model. This indicates whether respondents believe the vaccine programme would protect their chicken from disease or not. This variable was a dummy variable with value 1 if respondents 'believe' that the vaccine programme would protect their chicken from diseases and 0 otherwise.

\section{The study area}

This study is part of a larger project working on reducing the impact of infectious diseases on village poultry production in Ethiopia. It was conducted in Horro and Jarso districts, where mixed crop-livestock farming system is the mainstay of the community. These two districts were selected by the project considering agro-ecological characteristics of the areas and variation in poultry ecotype in the two districts. Horro is relatively humid area while Jarso is semi-arid. Horro is one of the surplus (crop) producing areas in the country while some parts of Jarso district fall under the government food safety net programme. Horro is located about $315 \mathrm{~km}$ west of Addis Ababa, West Ethiopia and Jarso is located about $550 \mathrm{~km}$ east of Addis Ababa. Livestock production is an integral part of semi-subsistent farming practice in both districts. Farmland in Horro is occupied by staple crops (wheat, teff, barley, beans and maize) during the cropping season and in Jarso it is predominantly covered by chat/khat which is the main source of cash income throughout the year. Chat (Catha edulis) is a stimulant perennial crop grown mainly for cash income and consumption in some parts of Ethiopia. Chat growing and marketing is one of the important livelihoods in the Jarso area. Vegetables and cereal crops such as wheat, barley and sorghum are also important crops for farmers in Jarso. The population in Jarso is predominantly Muslim while the population in Horro is Christian (Ethiopian Orthodox and Protestant). 
Table 1 Summary statistics for socioeconomic characteristics in a study of farmers' willingness to pay for village poultry vaccine services in Ethiopia, 2011

\begin{tabular}{llll}
\hline Variable name & Descriptions & Mean & Standard Deviations \\
\hline Gender & 0 if female; 1 if male & 0.93 & 0.25 \\
Age & Age of the household head (years) & 41.09 & 14.66 \\
Family size & Number of people living within the household & 6.43 & 2.39 \\
Education level & $0=$ None & 0.506 & 0.026 \\
& 1=has education & 1.27 & 1.40 \\
Total land size & Land size owned by the household in hectares & 8.06 & 7.76 \\
Poultry owned & Total number of poultry owned & 6.17 & 13.33 \\
Poultry lost & Total number of poultry lost in 12 months due to diseases & 5.79 & 6.47 \\
TLU & Tropical livestock unit using standard conversion factors & & \\
\hline
\end{tabular}

\section{The survey}

This study was approved by the University of Liverpool Committee on Research Ethics (reference RETH000410). A pilot household survey was conducted in Horro in February 2011 and included 19 farmers and the final survey was undertaken during the period April to June, 2011. The survey was conducted by trained enumerators and the researchers under close supervision and was administered to a total of 400 poultry keeping households randomly selected from eight 'Gandas'3 (as in government administration structure) which covers several villages. Thus, the total sample consisted of 200 households from each of the two districts of rural Ethiopia. A multistage sampling technique was applied to select sample households. Initially, the two districts were selected purposefully by the project considering difference in ecotype of poultry and agro-ecological and social differences between the two sites. Then four Gandas were considered from each district which gave eight Gandas from the two sites. Finally, 50 households were randomly selected from each of the eight Gandas using household lists provided by the development agents in each village. The four different bid amounts in the scenarios were randomly allocated across these respondents. The two scenarios were also presented to respondents in random order. Out of the 400 farmers surveyed for the two WTP elicitation scenarios, 21 of them answered 'Don't know' to either both scenarios or to one of the scenarios. These observations were excluded from the analysis as their responses were indeterminate. This gave us 379 useable observations from the two sites.

\section{Results and discussion}

\section{Sample characteristics and WTP responses}

Descriptive statistics of the socioeconomic variables for the survey respondents are presented in Table 1 . The average age

\footnotetext{
3 'Ganda' is the lowest administration unit in government administration structure and comprises several village centres.
}

of survey respondents was 41 and average family size was about 6 with an average land holding of 1.3 ha. The majority of the survey respondents (93\%) were male. This was expected as head of households are responsible for decisions related to finance and our survey targeted heads of households. About $51 \%$ of the respondents had some formal education. The average number of poultry owned by survey respondents was 8 and average number of poultry lost due to diseases in a year was 6 . On average, survey farmers had owned poultry for about 8 years. The Livestock asset base of the sample households measured by Tropical Livestock Unit (TLU ${ }^{4}$ ) was about six, on average.

We used a three-point scale rating (good, bad, and worst) to elicit respondents' perception about extent of poultry diseases problem in the area. This is presented in Table 2 together with data regarding farmers' access to animal health services and poultry production technical support from agricultural extension workers. The majority of the farmers perceived that the general condition of poultry disease was in either a bad or worst situation. About $34 \%$ of the survey respondents perceived that the extent of the rural poultry disease problem was bad while $33 \%$ of the survey respondents believe that it was in the worst condition. Most of the survey respondents perceived that the proposed vaccine programme would be effective in controlling poultry diseases in both scenarios, scenario one (86 \%) and scenario two (87\%). Only a limited proportion of respondents had access to poultry production extension services and about $75 \%$ of respondents had access to animal health services, although $42 \%$ of them did not have access to a poultry health service as the services are limited to some livestock species.

Out of the whole sample, 64 and $70 \%$ of respondents were willing to pay for the vaccination programme in programme 1 and programme 2 respectively (Table 3 ). We speculate that this enthusiastic response from farmers could possibly be due to the severity of poultry diseases they experience, which

${ }^{4}$ TLU is a standard conversion used to convert livestock of different species and age into a single measurement unit. 
Table 2 Farmers' access to support services and perception about problem of poultry diseases and effectiveness of the vaccine programmes

\begin{tabular}{|c|c|c|c|}
\hline Descriptions & $\begin{array}{l}\text { Respondents' } \\
\text { perception /access } \\
\text { to services }\end{array}$ & No. & Percen \\
\hline \multirow{3}{*}{$\begin{array}{l}\text { Perception about poultry diseases in } \\
\text { the area }(\mathrm{N}=379)\end{array}$} & Good & 122 & 32.2 \\
\hline & Bad & 129 & 34.0 \\
\hline & Worst & 128 & 33.8 \\
\hline \multirow{2}{*}{$\begin{array}{l}\text { Believe the vaccine programme } \\
\text { would control poultry diseases } \\
\text { effectively -programme } 1\end{array}$} & Yes & 324 & 85.5 \\
\hline & No & 55 & 14.5 \\
\hline \multirow{2}{*}{$\begin{array}{l}\text { Believe the vaccine programme } \\
\text { would control poultry diseases } \\
\text { effectively - programme } 2\end{array}$} & Yes & 331 & 87.3 \\
\hline & No & 48 & 12.7 \\
\hline \multirow{2}{*}{$\begin{array}{l}\text { Access to animal health service } \\
\qquad(\mathrm{N}=379)\end{array}$} & Yes & 284 & 74.9 \\
\hline & No & 95 & 25.1 \\
\hline \multirow{2}{*}{$\begin{array}{l}\text { Animal health clinic giving poultry } \\
\text { curative health service }(\mathrm{N}=284)\end{array}$} & Yes & 165 & 58.1 \\
\hline & No & 119 & 31.4 \\
\hline \multirow{2}{*}{$\begin{array}{l}\text { Access to extension support on } \\
\text { poultry production }(\mathrm{N}=379)\end{array}$} & Yes & 129 & 34 \\
\hline & No & 250 & 66 \\
\hline
\end{tabular}

often leads to loss of the whole flock. It may also be due to the expectation of benefits from chicken production as demand for eggs and chicken has grown in pre-urban areas over the last few years. Generally, there was a negative relationship between increase in bid amount and respondents' willingness to pay for vaccine services in both scenarios (Table 3). For programme 1, which was designed to deliver a vaccine service by village veterinary technicians, the 'yes' response falls from 80 to $54 \%$ as bid amount increases from ETB 65 to ETB 125 and then, unexpectedly and inexplicably, it rises to $59 \%$ for bid amount of ETB 155. The negative relationship for this programme is statistically significant at the 0.01 level of confidence for this scenario. For programme 2, which was designed to deliver a vaccine service by trained farmers, 'yes' response falls from 77 to $62 \%$ as bid amount increases from ETB 55 to ETB 110 and then it similarly rises to $72 \%$ for bid amount of ETB 135. The negative relationship for this scenario is not statistically significant. A possible explanation for this unexpected result is that farmers may use higher price as a signal for better quality vaccine service.

\section{Econometric result}

Estimates for exponential willingness for the two vaccination programmes using STATA version 12 is presented in Table 4 together with their mean marginal effects. The model result is in line with demand theory and indicates that respondents behave as rational consumers when faced with increase in cost. Whether respondents believed the proposed vaccine programmes would effectively protect their chicken from disease or not, age, education level, and region of the respondents were important in determining their willingness to pay. The Hosmer-Lemeshow goodness-of-fit test for the model was performed. Hosmer-Lemeshow $\mathrm{x}_{6}^{2}$ was $1.67(p=0.95)$ and $2.13(p=0.91)$ for estimated models of programme 1 and programme 2, respectively, which is consistent with the models fitting reasonably well. Additionally, the corresponding likelihood-ratio tests indicate the overall significance of the coefficients in the two models.

As expected, the coefficient on 'Lbid', log of the randomly assigned price levels to respondents, is negative and statistically significant in programme $1(p<0.01)$. In programme 2 also the coefficient is negative and statistically significant $(p<0.1)$. The negative sign denotes that the more the respondents are asked to pay, the lower the probability that respondents would be willing to pay for poultry vaccine service. Thus, if the bid amount goes up by $10 \%$, the probability of the respondent paying for the poultry vaccine service will decrease by 0.022 and 0.009 for programme 1 and programme 2 , respectively. The coefficient on 'believe' variable, which stands for whether respondents believe the vaccine programme would protect their chicken from diseases or not, is positive and statistically significant at the 0.01 level of confidence for both programmes. The positive sign indicates those who believe the vaccine programme would protect their chicken from disease are more likely to pay more. The probability that farmers who believe the vaccine would protect their chicken would be willing to pay, controlling for other factors, is 0.618 in programme 1 and 0.695 in programme 2 . This suggests that it is important to increase awareness of the efficacy of vaccine technology among village poultry keepers in order to ensure a wider uptake of vaccine technology. Likewise, the need to design an effective vaccination programme that could maintain a high level of efficacy is crucial.

The effects of the socio-demographic covariates are also as expected. The region, age, and education level of the household are important in determining farmers' willingness to pay for a poultry vaccine service. The variable $A g e$ is negative and statistically significant $(p<0.1)$ in programme 1 indicating older farmers are less likely to be willing to pay. This is in agreement with previous studies on farmers' willingness to pay for extension services and weather-index based insurance service in developing countries (Hill et al. 2013; Oladele 2008). An increase in age of the respondent by 1 year decreases the probability that a respondent would be willing to pay by 0.003 , on average. The variable education has a positive and statistically significant marginal effect at mean for programme 1 indicating educated respondents are more likely to be willing to pay. This finding is consistent with Holloway and Ehui (2001) in their study on willingness to pay for extension services and (Asrat et al. 2004) in their study on willingness to pay for soil conservation practice reported similar results. This could possibly be due to educated 
Table 3 Summary of farmers' willingness to pay responses to the two proposed vaccine programmes for each bid level and the whole sample presented in proportion

\begin{tabular}{|c|c|c|c|c|c|c|c|}
\hline \multicolumn{4}{|c|}{ Programme 1} & \multicolumn{4}{|c|}{ Programme 2} \\
\hline Bid & Yes & No & Percentage(Yes) & Bid & Yes & No & Percentage(Yes) \\
\hline 65 & 75 & 20 & 78.9 & 55 & 73 & 22 & 76.8 \\
\hline 95 & 61 & 35 & 63.5 & 85 & 66 & 30 & 68.8 \\
\hline 125 & 50 & 42 & 54.3 & 110 & 57 & 35 & 62.0 \\
\hline 155 & 57 & 39 & 59.4 & 135 & 69 & 27 & 71.9 \\
\hline Total & 243 & 136 & 64.1 & & 265 & 114 & 69.9 \\
\hline$\chi_{3}^{2}$ & & 13.85 & & & & 5.18 & \\
\hline$p$-value & & 0.003 & & & & 0.159 & \\
\hline
\end{tabular}

farmers' better ability to access and process information and recognize the risks of poultry diseases. It is also likely that educated farmers understand the importance of poultry vaccine and are aware of its possibility of reducing the impact of infectious poultry diseases.

The coefficient on region, a variable indicating region of respondents, is positive and statistically significant at $(p<0.1)$ for both programmes indicating farmers from Horro area are more likely to be willing to pay than those in Jarso. The marginal effect at mean for region denotes the probability that farmers would be willing to pay in Horro is higher by 0.094 in programme 1 and 0.141 in programme 2 . One possible explanation could be the difference in economic and cultural importance of chicken in the two regions. Horro farmers have relatively better access to markets and chickens have comparatively better market value, as chicken meat has higher cultural significance in Horro compared to Jarso. Farmers in Jarso grow a perennial crop, Khat, which generates cash throughout the year that could possibly meet their financial need, while farmers in Horro grow staple crops and may rely on small

Table 4 Probit estimates for exponential willingness to pay model and Median WTP

\begin{tabular}{|c|c|c|c|c|}
\hline \multirow[t]{2}{*}{ Variables } & \multicolumn{2}{|l|}{ Programme 1} & \multicolumn{2}{|l|}{ Programme 2} \\
\hline & Coefficient (SE) & Marginal effect (SE) & Coefficient (SE) & Marginal effect (SE) \\
\hline \multirow[t]{2}{*}{ Constant } & $2.383^{* *}$ & & -0.091 & \\
\hline & (1.109) & & $(1.221)$ & \\
\hline \multirow[t]{2}{*}{$\ln (\mathrm{Bid})$} & $-0.828 * * *$ & $-0.219 * * *$ & $-0.392 *$ & $-0.092 *$ \\
\hline & $(0.247)$ & $(0.059)$ & $(0.233)$ & $(0.054)$ \\
\hline \multirow[t]{2}{*}{ Believe } & $2.330 * * *$ & $0.618^{* * *}$ & $2.971 * * *$ & $0.695 * * *$ \\
\hline & $(0.288)$ & $(0.062)$ & $(0.441)$ & $(0.089)$ \\
\hline \multirow[t]{2}{*}{ Family size } & -0.014 & -0.004 & -0.009 & -0.002 \\
\hline & $(0.034)$ & $(0.009)$ & $(0.035)$ & $(0.001)$ \\
\hline \multirow[t]{2}{*}{ Age } & $-0.011^{*}$ & $-0.003^{*}$ & -0.008 & -0.002 \\
\hline & $(0.005)$ & $(0.002)$ & $(0.006)$ & $(0.001)$ \\
\hline \multirow[t]{2}{*}{ Male } & -0.144 & -0.038 & -0.250 & -0.059 \\
\hline & $(0.299)$ & $(0.079)$ & $(0.351)$ & $(0.082)$ \\
\hline \multirow[t]{2}{*}{ Education } & $0.348^{* *}$ & $0.092 * *$ & 0.241 & 0.056 \\
\hline & $(0.175)$ & $(0.046)$ & $(0.184)$ & $(0.043)$ \\
\hline \multirow[t]{2}{*}{ Region } & $0.353^{* *}$ & $0.092 * *$ & $0.605 * * *$ & $0.142 * * *$ \\
\hline & $(0.169)$ & $(0.046)$ & $(0.181)$ & $(0.042)$ \\
\hline \multirow[t]{2}{*}{ Total Poultry } & $0.019 *$ & $0.005^{*}$ & 0.004 & 0.001 \\
\hline & $(0.011)$ & $(0.003)$ & $(0.012)$ & $(0.003)$ \\
\hline Log likelihood & -179.27 & & -159 & \\
\hline Likelihood-Ratio test, $\chi_{8}^{2}$ & 96.61 & & 66.47 & \\
\hline Pseudo $\mathrm{R}^{2}$ & 0.28 & & 0.31 & \\
\hline $\mathrm{N}$ & 379 & & 379 & \\
\hline
\end{tabular}


Table 5 Mean and median WTP assed using parametric and nonparametric methods

\begin{tabular}{lllll}
\hline \multirow{2}{*}{ Measure } & Programme & WTP (ETB) & \multicolumn{2}{l}{$95 \%$ confidence interval $^{\mathrm{a}}$} \\
\cline { 4 - 5 } \cline { 4 - 4 } & & & Lower bound (ETB) & Upper bound (ETB) \\
\hline \multirow{2}{*}{ Mean } & Programme 1 & $87.4(3.28)$ & 80.97 & 93.82 \\
& Programme 2 & $80.0(2.90)$ & 74.32 & 85.68 \\
\multirow{3}{*}{ Median } & Programme 1 & 159.4 & 128.37 & 271.94 \\
& Programme 2 & 384.6 & 195.33 & 3093.4 \\
\hline
\end{tabular}

Standard errors given in parentheses for mean WTP

${ }^{\text {a }}$ Krinsky and Robb (95 \%) confidence interval was used for median WTP ruminants and poultry for cash needs. During the focus group discussions and fieldwork, poultry diseases were reported to be more important in Horro. Therefore, the regional difference in willingness to pay for a poultry vaccine service may be due to a combination of socioeconomic factors. It is, therefore, important to consider carefully generalization of the findings, as diversity in the micro and macro environments under which farmers keep poultry are likely to influence their WTP. The total number of poultry owned by the household was also statistically significant (at the $10 \%$ level) in programme 1 and it positively influenced farmers' willingness to pay, as expected.

\section{Willingness to pay estimates}

Mean and median WTP estimates for the two vaccine programmes are presented in Table 5. Parametric and nonparametric approaches were used to estimate farmers' willingness to pay for poultry vaccine services. The result from the estimates revealed that a lower bound for farmers' willingness to pay for a poultry vaccine service in programme 1 is ETB 87.4 (95\% confidence interval ETB 80.97-93.82) and that of programme 2 is ETB 80 (95\% confidence interval ETB 74.32-85.68) per year. Median WTP was calculated from the estimation result of the exponential probit model using equation (13) and given in Table 5. The farmers' median WTP for vaccine programme 1 is about ETB 159 and that of programme 2 is ETB 384.

\section{Conclusion}

This research investigated smallholder farmers' willingness to pay for village poultry vaccines against Newcastle Disease and Gumboro disease, in crop-livestock mixed farming systems in Ethiopia. Both parametric and non-parametric methods were employed in analysis of the data collected through a contingent valuation survey. The results indicate that a considerable proportion of interviewed farmers were willing to pay for the proposed poultry vaccine programmes. The estimated mean and median WTP also reveal that farmers are willing to pay for a village poultry vaccine service and appreciate the benefits of the vaccine technology. This indicates the existence of potential interest for vaccine use by farmers and the possibility of designing and implementing poultry disease control programmes. Therefore, there is a potential and prospect of reducing impacts of infectious poultry diseases and enhancing rural livelihoods through village poultry development. Livestock diversification plays a significant role in ensuring household food security (Megersa et al. 2014) and hence this study highlights the possibility of contributing to food security by reducing the impact of infectious diseases in rural poultry in the country.

This paper also identifies characteristics of the respondent that would be likely to influence farmers' WTP for village poultry vaccines. Results of the probit estimation show that WTP for a poultry vaccine service is influenced by age, education level of the respondent, respondents' perception about effectiveness of the vaccine and region of the respondent. Educated respondents are more likely to pay for a poultry vaccine service compared to uneducated and older farmers. This may suggest the need for awareness creation of the risk of poultry diseases and the options available to control them. Farmers who perceived the vaccine service would effectively protect their chickens from diseases were more likely to respond that they would pay for vaccine service. This possibly suggests that a vaccine programme that intends to control village poultry diseases needs to maintain an acceptable level of efficacy to build farmers' confidence towards the service. A more interesting result is the influence of respondents' region. Farmers from Horro, a staple crop growing area with limited cash crops, are more likely to be willing to pay compared with farmers from Jarso, a cash crop (Khat) growing area. It is, therefore, vital to consider the relative importance of chickens in a given area and the relative importance of chicken diseases to design a village poultry vaccine programme, which aims to benefit village poultry keepers.

This study provides important insights that could inform policies for reducing the impact of infectious diseases in village poultry in areas where they are prevalent. The case study from Ethiopia could be useful in other developing countries with similar production systems and socioeconomic 
environments. Complete generalization of the findings, however, need to be considered carefully. Further research in other parts of the developing world could be helpful in making comprehensive generalizations. It is also worth looking at farmers' WTP by further developing the WTP elicitation method and to back the vaccine programme by insurance/ compensation of loss if disease outbreaks occur after vaccination.

Acknowledgments We thank Biotechnology and Biological Sciences Research Council (BBSRC), the UK Department for International Development (DFID) and the Scottish Government for providing funding for the 'Reducing the impact of infectious disease on poultry production in Ethiopia' project under the Combating Infectious Diseases of Livestock for International Development (CIDLID) programme (BB/H009396/1). Farmers and development agents in Jarso and Horro districts of Ethiopia are highly appreciated for their assistance during the survey work. We would also like to thank the Chicken Health for Development (CH4D) project team members and enumerators for their cooperation.

\section{Appendix: Wording programme scenarios and questionnaire}

Currently, the existing poultry health service for village poultry in the country at large and in your area, in particular, is only a curative service. With the assistance of veterinary technicians and development agents, we are working to design a vaccination program for village poultry. We would like to ask you some questions about this program. Your answers will help us understand the demand for poultry vaccination and design the right kind of program. Please consider the program we describe carefully before you answer. If you have any questions about the program please ask us. We will be happy to answer any of your questions. If you would like to discuss with other members of your family before answering us - this is fine. Please take your time!

Scenario 1 In this case, the vaccine service will be offered by veterinary technicians at your own home. They will come to your house three times a year and will vaccinate your entire flock of birds. Three times is required for optimum control of disease. This vaccine will protect your birds against 'fingille" and Gumboro diseases. The vaccine will be administered orally, by mixing in drinking water or feed and/or eye drop method. The delivery of the program will be coordinated by the livestock agency of the district and relevant offices.

This service entails a cost to the household which you will have to pay in order to take advantage of the vaccination programme. It costs your household_ ETB to get the service each year. Please remember this is in addition to other living costs that your household spends in a year.

${ }^{5}$ Fingille is the local name for Newcastle disease
1. Did you understand the details of this vaccination program? A. Yes B. No

If respondent answers NO to question 1, go back and explain - till you receive the answer YES.

2. Would you pay the annual fee and take advantage of the vaccination programme?
1. Yes
2. No
3. I do not know

Scenario 2 We are also considering a different version of the above program. In this case, you will be given exactly the same vaccination service in every respect, except that the vaccination will be administered by yourself. You will have to go to the village centre on the assigned day and here you will be trained by the technician in the use of the vaccines. You will be given the vaccine, which you will have to give to your birds orally, by mixing this in their feed and drinking water and/or eye drop method. You will be asked to come to the village centre to collect the vaccine three times in the year.

This service entails a cost to the household which you will have to pay in order to take advantage of the vaccination programme. It costs your household___ETB to get the service each year. Please remember this is in addition to other living costs that your household spends in a year.

1. Did you understand the details of this vaccination program? A. Yes B. No

If respondent answers NO to question 1, go back and explain - till you receive the answer YES.

2. Would you pay the annual fee and take advantage of the vaccination program?
a. Yes
b. No
c. I do not know

Open Access This article is distributed under the terms of the Creative Commons Attribution 4.0 International License (http://creativecommons.org/licenses/by/4.0/), which permits unrestricted use, distribution, and reproduction in any medium, provided you give appropriate credit to the original author(s) and the source, provide a link to the Creative Commons license, and indicate if changes were made.

\section{References}

Aklilu, H. A., Almekinders, C. J., Udo, H. M., \& Van der Zijpp, A. J. (2007). Village poultry consumption and marketing in relation to gender, religious festivals and market access. Tropical Animal Health and Production, 39(3), 165-177. 
Arrow, K., \& Solow, R. (1993). Report of the NOAA panel on contingent valuation. Washington: National Oceanic and Atmospheric Administration.

Asrat, P., Belay, K., \& Hamito, D. (2004). Determinants of farmers' willingness to pay for soil conservation practices in the southeastern highlands of Ethiopia. Land Degradation \& Development, 15(4), 423-438. doi:10.1002/ldr.623.

Bateman, I. J., Carson, R. T., Day, B., Hanemann, M., Hanley, N., Hett, T., et al. (2002). Economic valuation with stated preference techniques: a manual (Economic valuation with stated preference techniques: a manual). Cheltenham: Edward Elgar Publishing Ltd

Bennett, R., \& Balcombe, K. (2012). Farmers' willingness to pay for a tuberculosis cattle vaccine. Journal of Agricultural Economics, 63(2), 408-424. doi:10.1111/j.1477-9552.2011.00330.x.

Brouwer, R. O. Y., Akter, S., Brander, L., \& Haque, E. (2008). Economic valuation of flood risk exposure and reduction in a severely flood prone developing country. Environment and Development Economics, 14(03), 397. doi:10.1017/ s1355770x08004828.

Carson, R. T. (1998). Valuation of tropical rainforests: philosophical and practical issues in the use of contingent valuation. Ecological Economics, 24(1), 15-29.

Carson, R. T., Flores, N. E., Martin, K. M., \& Wright, J. L. (1996). Contingent valuation and revealed preference methodologies: comparing the estimates for quasi-public goods. Land Economics, 72(1), 80-99. doi:10.2307/3147159.

Copland, J. W., \& Alders, R. G. (2005). The Australian village poultry development programme in Asia and Africa. World's Poultry Science Journal, 61, 32-37.

CSA. (2011). Agricultural sample survey: Report on livestock and livestock characterstics. Addis Ababa: Central Statistical Agency.

Degefu, H., Balcha, M., Yohannes, M., \& Getachew, M. (2010). Seroprevalece of Infectious Bursal Disease in backyard chickens of Oromia regional state, Ethiopia. Veterinary Research, 3(4), 89-93.

Delgado, C., Rosegrant, M., Steinfeld, H., Ehui, S., \& Courbois, C. (1999). Livestock to 2020: the next food revolution. Food, Agriculture, and the Environment Discussion Paper. Washington: International Food Policy Research Institute.

Dessie, T., \& Ogle, B. (2001). Village poultry production systems in the central highlands of Ethiopia. Tropical Animal Health and Production, 33(6), 521-537.

Gari, G., Tilahun, G., \& Dorchies, P. (2008). Study on poultry coccidiosis in Tiyo District, Arsi Zone. International Journal of Poultry Science, 7(3), 251-256.

Gueye, E. F. (2002). Employment and income generation through family poultry in low-income food-deficit countries. World's Poultry Science Journal, 58(4), 501-517.

Haab, T. C., \& McConnell, K. E. (1997). Referendum models and negative willingness to pay: alternative solutions. Journal of Environmental Economics and Management, 32(2), 251-270.

Haab, T. C., \& McConnell, K. E. (1998). Referendum models and economic values: theoretical, intuitive, and practical bounds on willingness to pay. Land Economics, 74(2), 216-229. doi:10.2307/ 3147052.

Haab, T. C., \& McConnell, K. E. (2002). Valuing environmental and natural resources: The econometrics of non-market valuation: New Horizons in Environmental Economics. Cheltenham: Edward Elgar Publishers.

Halima, H., Neser, F. W. C., Marle-Koster, E., \& Kock, A. (2007). Village-based indigenous chicken production system in north-west Ethiopia. Tropical Animal Health and Production, 39(3), 189-197. doi:10.1007/s11250-007-9004-6.
Hanemann, W. M. (1984). Welfare evaluations in contingent valuation experiments with discrete responses. American Journal of Agricultural Economics, 66(3), 332-341. doi:10.2307/ 1240800

Hanemann, W. M. (1994). Valuing the environment through contingent valuation. The Journal of Economic Perspectives, 8(4), 19-43. doi: $10.2307 / 2138337$

Hill, R. V., Hoddinott, J., \& Kumar, N. (2013). Adoption of weatherindex insurance: learning from willingness to pay among a panel of households in rural Ethiopia. Agricultural Economics, 44(4-5), 385-398. doi:10.1111/agec.12023.

Holloway, G. J., \& Ehui, S. K. (2001). Demand, supply and willingnessto-pay for extension services in an emerging-market setting. American Journal of Agricultural Economics, 83(3), 764-768. doi:10.1111/0002-9092.00205.

Jenbreie, S., Ayelet, G., Gelaye, E., Kebede, F., Lynch, S. E., \& Negussie, H. (2012). Infectious bursal disease: seroprevalence and associated risk factors in major poultry rearing areas of Ethiopia. Tropical Animal Health and Production, 45(1), 75-79.

Johannesson, M., Jonsson, B., \& Borgquist, L. (1991). Willingness to pay for antihypertensive therapy-results of a Swedish pilot study. Journal of Health Economics, 10(4), 461-473.

Kassie, G. T., Abdulai, A., \& Wollny, C. (2009). Valuing traits of indigenous cows in Central Ethiopia. Journal of Agricultural Economics, 60(2), 386-401. doi:10.1111/j.1477-9552.2008. 00191.x.

Loomis, J., Kent, P., Strange, L., Fausch, K., \& Covich, A. (2000) Measuring the total economic value of restoring ecosystem services in an impaired river basin: results from a contingent valuation survey. Ecological Economics, 33(1), 103-117. doi:10.1016/S09218009(99)00131-7.

McLeod, A., \& Rushton, J. (2007). Economics of animal vaccination. Revue Scientifique et Technique, 26(2), 313-326.

Megersa, B., Markemann, A., Angassa, A., \& Zárate, A. V. (2014). The role of livestock diversification in ensuring household food security under a changing climate in Borana, Ethiopia. Food Security, 6(1), 15.

Merrett, S. (2002). Deconstructing households' willingness-to-pay for water in low-income countries. Water Policy, 4(2), 157-172. doi: 10.1016/S1366-7017(02)00002-8

Mitchell, R. C., \& Carson, R. T. (1989). Using surveys to value public goods: the contingent valuation method. Washington: Resources for the future.

Msoffe, P. L., Bunn, D., Muhairwa, A. P., Mtambo, M. M., Mwamhehe, H., Msago, A., et al. (2010). Implementing poultry vaccination and biosecurity at the village level in Tanzania: a social strategy to promote health in free-range poultry populations. Tropical Animal Health and Production, 42(2), 253-263. doi:10.1007/s11250-009-9414-8.

Oladele, O. I. (2008). Factors determining farmers' willingness to pay for extension servics in Oyo State, Nigeria. Agricultura Tropica Et Subtropica, 41, 4 .

Ouma, E., Abdulai, A., \& Drucker, A. (2007). Measuring heterogeneous preferences for cattle traits among cattle-keeping households in East Africa. American Journal of Agricultural Economics, 89(4), 10051019.

Scarpa, R., Drucker, A. G., Anderson, S., Ferraes-Ehuan, N., Gómez, V., Risopatrón, C. R., et al. (2003). Valuing genetic resources in peasant economies: the case of 'hairless' creole pigs in Yucatan. Ecological Economics, 45(3), 427-443. doi: 10.1016/S0921-8009(03)00095-8.

Swallow, B. M., \& Woudyalew, M. (1994). Evaluating willingness to contribute to a local public good: application of contingent valuation to tsetse control in Ethiopia. Ecological Economics, 11(2), 153-161. doi:10.1016/0921-8009(94)90025-6.

Umali, D. L., Feder, G., \& de Haan, C. (1994). Animal health services: finding the balance between public and private delivery. World Bank Research Observer, 9(1), 71-96. 
Wambura, P. N., Kapaga, A. M., \& Hyera, J. M. (2000). Experimental trials with a thermostable Newcastle disease virus (strain I2) in commercial and village chickens in Tanzania. Preventive Veterinary Medicine, 43(2), 75-83.

Whitelaw, C. B., \& Sang, H. M. (2005). Disease-resistant genetically modified animals. Revue Scientifique et Technique, 24(1), 275-283.

Whittington, D., Briscoe, J., Mu, X., \& Barron, W. (1990). Estimating the willingness to pay for water services in developing countries: a case study of the use of contingent valuation surveys in Southern Haiti. Economic Development and Cultural Change, 38(2), 293-311. doi: $10.2307 / 1154028$.

Zeleke, A., Sori, T., Gelaye, E., \& Ayelet, G. (2005). Newcastle disease in village chickens in the southern and Rift Valley Districts in Ethiopia. International Journal of Poultry Science, 4(7), 507-510.

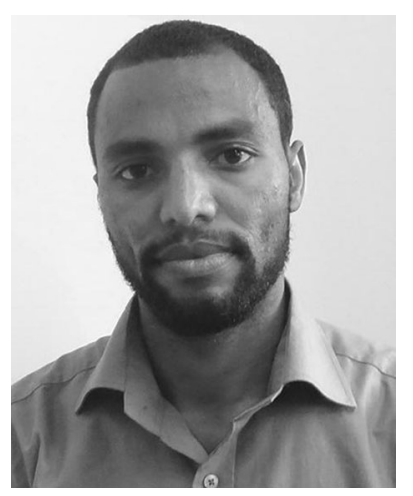

Zelalem G. Terfa is a $\mathrm{PhD}$ candidate at the University of Liverpool. His current research includes investigating the economic value of animal health services and animal genetic resources in Ethiopia in an effort to reduce the impact of infectious diseases and improve rural farmers' access to food. His research interests include understanding farmers' economic decision behaviour and preferences in a production risk environment by employing stated preference approaches and discrete choice modelling.

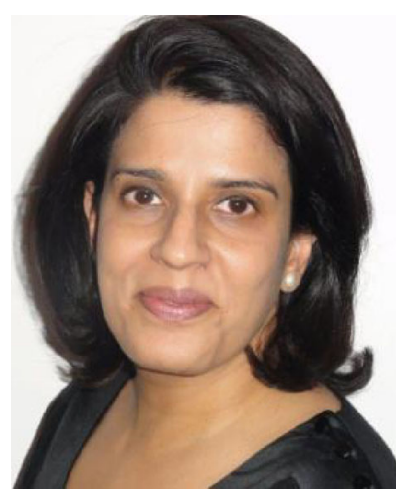

Dr Supriya Garikipati is an Associate Professor in Development Studies at the University of Liverpool and Group Leader of DRIVE (Development Research Initiative). She holds a $\mathrm{PhD}$ in economics from the University of Cambridge, UK. Within development studies, her research mainly examines the impact of public policy interventions on rural livelihoods with a focus on gender and poverty

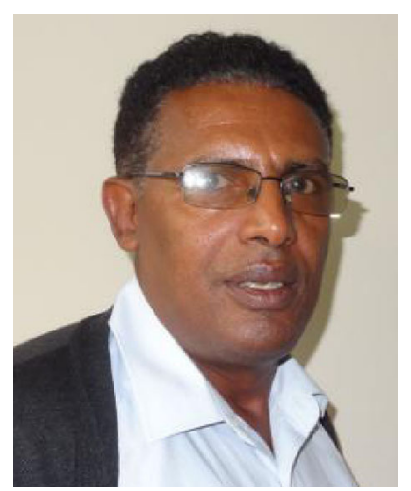

Tadelle Dessie is a senior scientist at the International Livestock Research Institute (ILRI) based in Ethiopia, working on animal genetics and breeding. His research interests include the understanding and sustainable improvement of the production and productivity levels of indigenous African livestock.

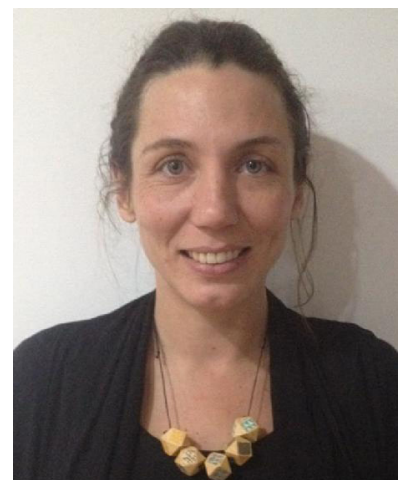

Stacey E. Lynch is a microbiologists and holds a $\mathrm{PhD}$ from Melbourne University in Australia in viral pathogenesis and diagnostics. During her post-doctoral training, she held a joint position with the University of Liverpool and the International Livestock Research Institute, where she implemented diagnostic laboratory assays for the Chicken Health 4 Development project and provided project management support for sample collection. Her area of research interest focuses on the use of smarter surveillance systems and viral molecular epidemiology. She is currently coordinating a mosquito-borne virus surveillance program for the Victorian State Government, Australia.

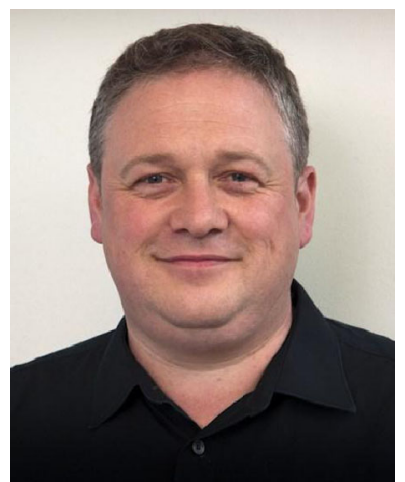

Paul Wigley is Reader in Foodborne Zoonoses in the Institute for Infection and Global Health at the University of Liverpool. His main expertise is in the immunobiology of infectious disease in chicken. He leads a number of projects on foodborne bacterial infections in chicken and other livestock species with specific focus on applying these findings to the reduction of foodborne disease and the improvement of livestock health and welfare. 


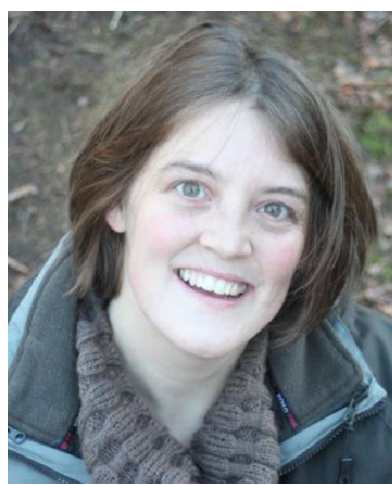

Judy Bettridge is a veterinary epidemiologist at the University of Liverpool, currently completing a $\mathrm{PhD}$ looking at the epidemiology and ecology of infectious diseases in village chickens. She holds a Masters degree in Veterinary Infection and Disease Control and has previously worked on the ecology of Lyme disease in the UK. Her research interests include understanding the ecology of animal pathogens and how these are influenced by human behaviour.

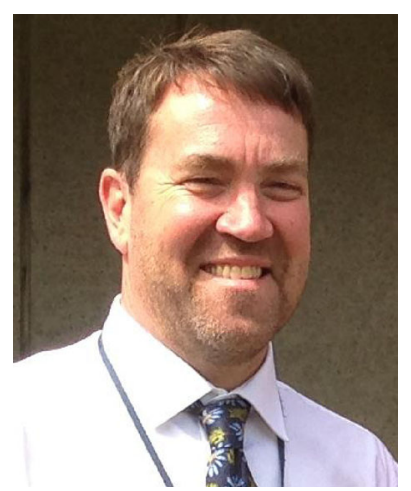

Rob Christley holds a $\mathrm{PhD}$ from the University of Sydney (Australia) and is a Reader in Epidemiology in the Institute of Infection and Global Health at the University of Liverpool. He has worked extensively in interdisciplinary research linking social and natural sciences at the interface of human and animal health. 